\title{
VEIN OF GALEN ANEURYSM DIAGNOSED BY ANTENATAL ULTRASONOGRAPHY: A RARE CASE
}

Satyabhuwan Singh Netam¹, Sanjay Kumar², Rajesh K. Singh³, Vishal K. Jain ${ }^{4}$, Swati Gupta ${ }^{5}$

\section{HOW TO CITE THIS ARTICLE:}

Satyabhuwan Singh Netam, Sanjay Kumar, Rajesh K. Singh, Vishal K. Jain, Swati Gupta. "Vein of Galen Aneurysm Diagnosed by Antenatal Ultrasonography: A Rare Case". Journal of Evolution of Medical and Dental Sciences 2015; Vol. 4, Issue 43, May 28; Page: 7576-7579, DOI: 10.14260/jemds/2015/1100

ABSTRACT: Vein of galen aneurysm is a rare congenital vascular malformation in which there is shunting of arterial flow in to dilated cerebral vein along the tectum which drains in to straight sinus. Majority of cases of perinatal mortality in case of vein of galen are caused by congestive cardiac failure. Vein of galen is classified according to clinical presentation. Due to advancement in ultrasonography and color Doppler this malformation can be detected early and management can be planed. Advancement in endovascular neurointerventional technique made possible to treat this malformation if the neonate sustained for some time. Here we present a case of vein of galen aneurysm diagnosed in a routine antenatal ultrasonography.

KEYWORDS: Vein of galen, Aneurysm, Antenatal ultrasound.

INTRODUCTION: Vein of Galen aneurysm is a very rare entity among all the intracranial anomalies. Its incidence is less than $1 \%$ with prevalence of 1 in $25000 .{ }^{1}$ Vein of Galen malformation occur at $6^{\text {th }}$ to 11 week of gestation, however its diagnosis is made in late antenatal or postnatal period. Third trimester scan has a very important role in the evaluation of this entity as there is evidence of approximately $50 \%$ mortality in the neonatal period.

CASE REPORT: A 27 years old second gravida patient came for routine third trimester antenatal scan. On ultrasound the pregnancy was 32 weeks. There was an intracranial cystic lesion along the third ventricle and pineal gland region (Fig. No. 1). On colour Doppler the lesion shows colour flow with "swirl sign" (Fig. No. 2). The lesion appears to be in continuation with the falcine sinus. No other associated findings were seen except mild dilatation of both lateral ventricles (Fig. No. 3). The delivery was full term and normal delivery. A male child was born who was immediately shifted to NICU due to suspicion of meconium aspiration. The condition of the neonate was continuously deteriorating. On third postnatal day the neonate died of perinatal birth asphyxia, respiratory failure and shock as per clinical record.

DISCUSSION: Vein of Galen malformations is termed after "Galen of Pergamon" a Roman physician and philosopher. ${ }^{2}$ Anatomically the vein of Galen is the deep cerebral vein formed posterior to the pineal gland by joining of the two internal cerebral veins. It courses upward around the splenium of the corpus callosum and drains the veins of the diencephalon, basal ganglia, and mid brain. Aneurysm of vein of galen is a dilatation either due to pressure overload or associated arterio-venous malformation. First case of vein of galen aneurysm was described by jagger et al. ${ }^{3}$ Vein of galen malformation has been classified variedly by different author. According to the Lasjaunias classification which is based on the origin and number of feeding arteries into choroidal and mural type. 4 
By Yasargil classification it is divided into four types; type I shows small cisternal fistula between the vein of Galen and the pericallosal arteries or posterior cerebral artery, type II showing multiple fistulae between the vein of Galen and the thalamoperforating vessels, type III is a mixed variety of type I and II and type IV: parenchymal arteriovenous malformation (AVM) with drainage into the vein of Galen. ${ }^{5}$

Embryologically it is said that the primary cerebral vasculature differentiate into arteries and veins by 7 to 9 wks. of gestation. The galenic system arises from the choroidal vein and the arteriovenous fistula. As there is persistence of fistulous communication between primitive pia arachnoidal arteries and plial veins which cross each other at right angles at later stages of development leading to the malformation. ${ }^{6}$

It is also illustrated by some authors that the aneurysmal dilatation is of the median prosencephalic vein. Normally the median prosencephalic vein which is the precursor of vein of galen regress by 9 to $11^{\text {th }}$ week but in cases where normal mature vasculature is not formed it fails to regress. In its association there is absence of straight sinus in $50 \%$ of patients with persistence of falcine sinus. Thereby the persisting MPV drains into the falcine sinus. The exact pathogenesis leading to aneurysmal dilatation is still unclear, however it is presumed due to the immature vasculature and the multiple Arterio-venous fistulous communication leading to pressure overload and aneurysmal dilatation. ${ }^{7}$ The causes and pattern of structural damage has been documented by Norman and Becker. According to them intracranial lesion on autopsy included hemorrhage, infarction, periventricular leukomalacia and cortical laminar necrosis. ${ }^{8}$ Congestive heart failure occurs in the neonate or infant as a consequence of rapid AV shunting through a cerebral AVM. ${ }^{9}$ Thrombosis of deep cerebral veins, the vein of Galen, or sinus system has been reported in some subjects with AVG, occasionally, thrombosis is associated with venous infarction..$^{9,10,11}$

CONCLUSION: Aneurysmal dilatation of Vein of Galen is a critical condition leading to poor prognosis of the patient if untreated. Though it is very difficult to perform intervention procedures in newborns but if the patient can be sustained for few months conservatively then intervention do have a role in life saving. It is very important to have a careful assessment about the malformation type and associated finding to plan the treatment. With newer technologies and better tools in hand increased number of cases being diagnosed and being treated with more confidence which have shown significant results.

\section{REFERENCES:}

1. Vein of Galen Aneurysmal Malformations: An Ultrasonographic Incidental Finding-A Case Report, S. Stephan, ${ }^{1}$ G. Rodesch, ${ }^{2}$ E. Elolf, ${ }^{3}$ D. Wiemann, ${ }^{1}$ and G. Jorch. ${ }^{1}$ Volume 2012 (2012), Article ID824284, http://dx. doi.org/10.1155/2012/824284.

2. Alexander MJ, Spetzler RF. Pediatric neurovascular disease, surgical, endovascular, and medical management. Thieme Medical Pub. (2006) ISBN: 1588903680.

3. Jaeger Jr, Forbes RP, Dandy WE: Bilateral congenital cerebral arteriovenous communications aneurysm. Trans Am Neurol Ass 63: 17361937.

4. Lasjaunias Pierre L. Vascular diseases in neonates, infants and children. Springer, 1997. ISBN: $3540608451,9783540608455$.

5. AK. Gupta, DR. Varma "Vein of Galen malformations: Review" Neurology India March 2004 Vol 52 Issue 1. 


\section{CASE REPORT}

6. Padget DH: The cranial venous system in man in reference to development, adult configuration and relation to the arteries. Am J Anat 98: 30755, 1956.

7. Raybaud CA, Strother CM, Hald JK. Aneurysms of the vein of Galen: embryonic considerations and anatomical features relating to the pathogenesis of the malformation. Neuroradiology 1989; 31: 109-28.

8. Norman MG, Becker LE. Cerebral damage in neonates resulting from arteriovenous malformation of the vein of Galen. J Neurol Neurosurg Psychiatry 1974; 37: 252-8.

9. Silverman BK, Breck T, Craig J, Nadas AS. Congestive failure in the newborn caused by cerebral A-V fistula. Am J Dis Child 1955; 89: 539-43.

10. Gold AP, Ransohoff J, Carter S. Vein of Galen malformation. Acta Neurol Scand 1964; suppl 11, 40: 1-31.

11. Stern L, Ramos AD, Wiglesworth FW. Congestive heart failure secondary to cerebral arteriovenous aneurysm in the newborn infant. Am J Dis Child 1968; 115: 581-7.

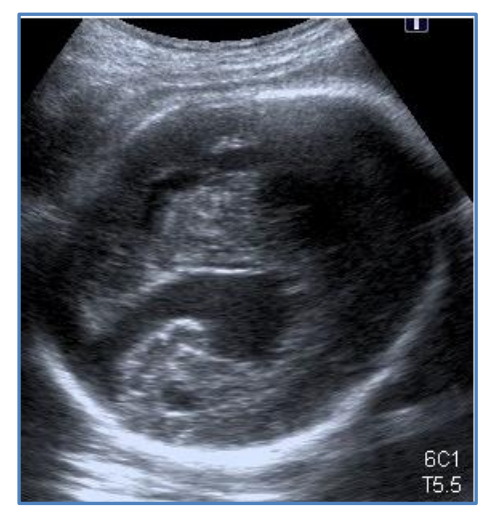

Fig. 1: Cystic Lesion in Brain

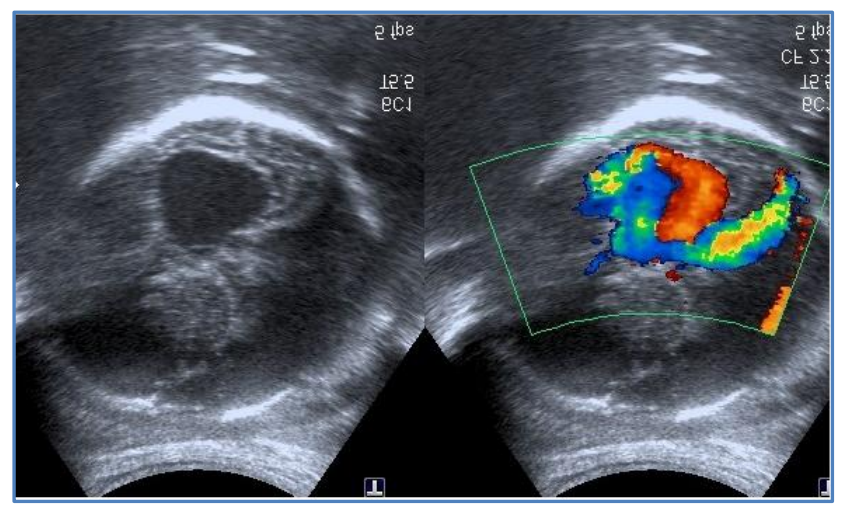

Fig. 2: Cystic Lesion of Brain

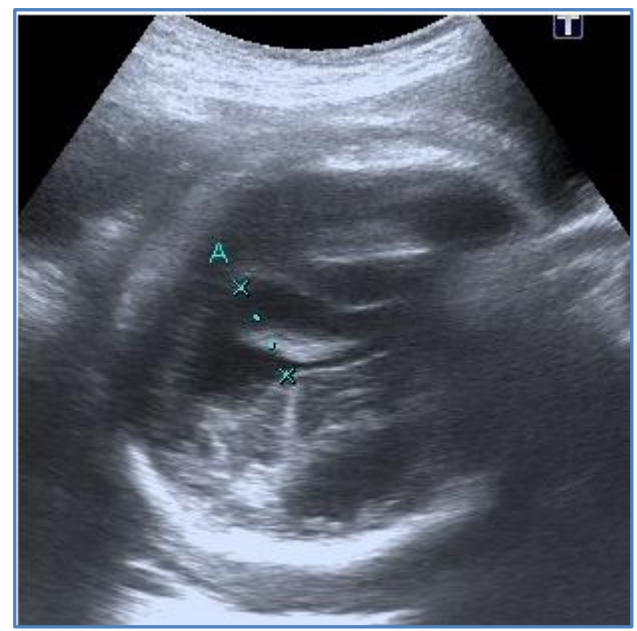

Fig. 3: Mild Dilated Lateral Ventricle 


\section{CASE REPORT}

\section{AUTHORS:}

1. Satyabhuwan Singh Netam

2. Sanjay Kumar

3. Rajesh K. Singh

4. Vishal K. Jain

5. Swati Gupta

\section{PARTICULARS OF CONTRIBUTORS:}

1. Associate Professor, Department of Radiodiagnosis, Pt JNM Medical College, Raipur, CG.

2. Associate Professor, Department of Radiodiagnosis, Pt JNM Medical College, Raipur, CG.

3. Assistant Professor, Department of Radiodiagnosis, Pt JNM Medical College, Raipur, CG.

FINANCIAL OR OTHER COMPETING INTERESTS: None
4. Assistant Professor, Department of Radiodiagnosis, Pt JNM Medical College, Raipur, CG.

5. Senior Resident, Department of Radiodiagnosis, Pt JNM Medical College, Raipur, CG.

\section{NAME ADDRESS EMAIL ID OF THE}

\section{CORRESPONDING AUTHOR:}

Satyabhuwan Singh Netam,

D-20, avani vihar, daldalseoni Road, Mova, Raipur, CG, India.

E-mail: sbsnetam@yahoo.com

Date of Submission: 08/05/2015. Date of Peer Review: 09/05/2015. Date of Acceptance: 20/05/2015. Date of Publishing: 28/05/2015. 